\title{
Spatially Resolved Dissolution and Speciation Changes of ZnO Nanorods during Short-Term in Situ Incubation in a Simulated Wastewater Environment
}

\author{
Miguel A. Gomez-Gonzalez, ${ }^{*},+$,\# Mohamed A. Koronfel,† Angela Erin Goode,† Maryam Al-Ejji, † Nikolaos

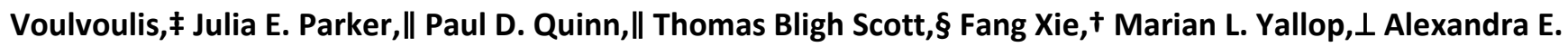 \\ Porter, ${ }^{*},+$,\# and Mary P. Ryant \\ ${ }^{\dagger}$ Department of Materials and London Centre for Nanotechnology, Imperial College London, London SW7 2AZ, United Kingdom \\ ${ }^{\ddagger}$ Centre for Environmental Policy, Imperial College London, London SW7 2AZ, United Kingdom \\ "Harwell Science and Innovation Campus, Diamond Light Source, Ltd., Didcot, Oxfordshire OX11 ODE, United Kingdom \\ ${ }^{\S}$ Interface Analyses Centre, University of Bristol, Bristol BS2 8BS, United Kingdom \\ ${ }^{\perp}$ School of Biological Sciences, University of Bristol, Bristol BS8 1TQ, United Kingdom
}

ABSTRACT: Zinc oxide engineered nanomaterials (ZnO ENMs) are used in a variety of applications worldwide due to their optoelectronic and antibacterial properties with potential contaminant risk to the environment following their disposal. One of the main potential pathways for $\mathrm{ZnO}$ nanomaterials to reach the environment is via urban wastewater treatment plants. So far there is no technique that can provide spatiotemporal nanoscale information about the rates and mechanisms by which the individual nanoparticles transform. Fundamental knowledge of how the surface chemistry of individual particles change, and the heterogeneity of transformations within the system, will reveal the critical physicochemical properties determining environmental damage and deactivation. We applied a methodology based on spatially resolved in situ X-ray fluorescence microscopy (XFM), allowing observation of real-time dissolution and morphological and chemical evolution of synthetic template-grown $\mathrm{ZnO}$ nanorods ( $~ 725 \mathrm{~nm}$ length, $\sim 140 \mathrm{~nm}$ diameter). Core-shell ZnO-ZnS nanostructures were formed rapidly within 1 $\mathrm{h}$, and significant amounts of $\mathrm{ZnS}$ species were generated, with a corresponding depletion of $\mathrm{ZnO}$ after $3 \mathrm{~h}$. Diffuse nanoparticles of $\mathrm{ZnS}, \mathrm{Zn}_{3}\left(\mathrm{PO}_{4}\right)_{2}$, and $\mathrm{Zn}$ adsorbed to Fe-oxyhydroxides were also imaged in some nonsterically impeded regions after $3 \mathrm{~h}$. The formation of diffuse nanoparticles was affected by ongoing ZnO dissolution (quantified by inductively coupled plasma mass spectrometry) and the humic acid content in the simulated sludge. Complementary ex situ X-ray absorption spectroscopy and scanning electron microscopy confirmed a significant decrease in the ZnO contribution over time. Application of time-resolved XFM enables predictions about the rates at which ZnO nanomaterials transform during their first stages of the wastewater treatment process.

KEYWORDS: ZnO nanomaterials, X-ray fluorescence microscopy, scanning electron microscopy, in situ ZnO dissolution, spatially resolved ZnO transformations 
Zinc oxide engineered nanomaterials ( $\mathrm{n} \mathrm{nO}$ ENMs) are incorporated into a wide range of consumer products, such as sunscreens, personal care products, and antibacterial agents, raising concerns about their potential impact as a pollutant following their inevitable release into the environment. The annual production of ZnO ENMs was estimated to be 1600 tons in EU countries, a marked increase on previous estimates.(1) One of the primary pathways for environmental exposure to $\mathrm{ZnO}$ ENMs is via their passage through municipal sewage systems. $(2,3)$ Current concentrations of ZnO ENMs in municipal waters are predicted to be of the order of $\mathrm{mg} \mathrm{L}^{-1}$.(4) Variations in the physicochemical properties (such as size, surface chemistry, and aggregation state) of ZnO ENMs in aqueous environmental media will generate a highly complex mixture of transformed ENMs with very varied properties and behavior.(5) Transformation of ZnO ENMs may inhibit bacterial processes within urban wastewater treatment plants (WWTPs) and may adversely affect the health of organisms in soils and waters once treated material is released back into the natural environment, $(6,7)$ though some research indicates minimal impacts.(8) More detailed knowledge and understanding of the nature of these transformations and the time-scales over which transformations can occur is essential for predicting likely outcomes of the interactions between individual ZnO ENMs and biota and the overall implications for ecosystem health. The toxicity of ZnO ENMs to biota is expected to be strongly influenced by their surface chemistry, speciation, and transformation. These thermodynamically driven processes are influenced by a range of environmental factors, including temperature, $\mathrm{pH}$, organic matter content, and the presence of other compounds and colloids. $(9,10)$ Above a threshold concentration, zinc ions released from ENMs dissolution can be highly toxic, $(11,12)$ but chemical reactions, such as sulfidation or complexation with organic carbon within environmental systems, can reduce their toxicity by effectively trapping free $\mathrm{Zn}^{2+}$ ions. $(13,14)$ The speciation and transformation of $\mathrm{ZnO}$ ENMs within a pilot WWTP have been studied previously using bulk analytical techniques.(2,15) Applying X-ray absorption near edge spectroscopy (XANES), Ma et al.(2) found that ZnO particles transform into a complex mixture of $\mathrm{ZnS}, \mathrm{Zn}_{3}\left(\mathrm{PO}_{4}\right)_{2}$, and $\mathrm{Zn}$ adsorbed to Fe oxy/hydroxides within the biosolids generated at the WWTPs. However, bulk analyses were conducted, with no spatially resolved information about the particle distribution, morphology, and size, or the local degree of $\mathrm{ZnO}$ particle transformation. One report showed a conversion of almost $100 \%$ of $\mathrm{ZnO}$ to $\mathrm{ZnS}$ in an aquatic medium with a high enough sulfide concentration and incubation time (5 days).(16) These transformations will all be critical determinants of the ZnO ENMs' end-point toxicity. Natural organic matter (NOM) is present in all urban WWTPs and therefore must be taken into account in the kinetics of ZnO ENM transformations and their behavior during wastewater treatment processes.(17) Organic matter, including humic and fulvic acids, may sorb to the surface of the ENMs, altering their surface properties. This will influence factors such as agglomeration of the ENMs and their dissolution, which, in turn, will affect the ENM's settling, transport, physico-chemistry, and behavior within sludges. $(18,19)$ These organic molecules usually form ligands on the surface of the ENMs, however, their influence on subsequent chemical transformations of the ENMs is less clear. Bian et al.(20) reported that ZnO ENMs became more stable in the presence of humic acid $\left(10-100 \mathrm{mg} \mathrm{L}^{-1}\right)$. However, a neutral $\mathrm{pH}$ was 
used for their analysis, which is in contrast to the acidic $\mathrm{pH}$ found in a primary sludge within a WWTP $(\mathrm{pH} \sim 4.5)$.

The dissolution rate for ZnO ENMs is not the sole factor that will influence their physicochemistry (including morphology, size, and surface chemistry). Alterations to the bulk and surface chemistry of the nanoparticles and their transformation into so-called "daughter particles" will affect where they accumulate and their ultimate bioreactivity. These processes will occur dynamically within, for example, the aqueous sludges of WWTPs, and assessment of ZnO ENMs transformations requires the development of spatially resolved in situ methods to track any physicochemical changes in real-time. Few techniques are capable of visualizing dissolution kinetics and chemical transformations of the individual engineered nanomaterials or of measuring these properties over relatively short-range time scales ( hours). Chemical analysis of nanomaterials has mostly been limited to static techniques, such as nanoanalytical electron energy loss spectroscopy (EELS); these methods are limited by the fact that the samples must be imaged under high-vacuum conditions.(21) Dynamic information can now be generated using in situ electron microscopy holders, however, the samples will undergo electron beam damage induced by water hydrolysis that will cause artifacts.(22,23) Hard X-ray fluorescence microscopy (XFM), $(24,25)$ has a spatial resolution ranging from around 25 to 100 $\mathrm{nm}$, provided by the Fresnel X-ray zone plates or KB mirrors, and has higher energy resolution than nanoanalytical spectroscopy in electron microscopes.(26-28) This technique offers the capability to monitor dynamic changes to the morphology and surface chemistry of the ENMs, in situ, within relevant hydrated environments, $(29,30)$ with an outstanding combination of energy and spatial resolution. In recent years, XFM has emerged as a promising technique for imaging environmental samples due to its high spatial resolution and sensitivity to a range of elements (depending on their absorption edges). This technique has been applied to study $\mathrm{Zn}$ accumulation and quantification within relevant biological(31-33) and environmental samples,(34,35) with only a few in situ micro-X-ray analyses previously reported.(36) Here, we report on $\mathrm{ZnO}$ speciation and morphological changes studied by in situ XFM within relevant simulated sludges. A relevant aqueous component of wastewater sludge, humic acid, was used to demonstrate that the XFM technique can be utilized to characterize chemical and morphological transformations of individual nanomaterials in aqueous environments in situ. It is only by applying this simplified system, instead of a more complex real sludge, that we can generate accurate proof-of-concept of the feasibility of the technique. An X-ray absorption spectrum was generated by acquiring multi-energy XFM images along the Zn K-edge, after plotting the mean $\mathrm{Zn}$ intensity of the image versus the energy. Here, the linear combination fitting of this spectrum against the $\mathrm{Zn}$-standard spectra(37) was used to confirm the nature of the $\mathrm{Zn}$ species after the in situ incubation by XFM.

Previously published data showed that ZnO rods with lengths ranging from 687 to $1512 \mathrm{~nm}$ are present in consumer products, together with even bigger aggregates.(38) Therefore, we selected large $\mathrm{ZnO}$ nanorods deposited over silicon nitride windows to compare $\mathrm{ZnO}$ transformations in situ before and after short-time incubations in relevant simulated sludge to fix the position of the rods for real-time mapping. The aims were to acquire: (i) spatially resolved maps showing the transformations of $\mathrm{ZnO}$ nanorods in a simulated WWTP medium, (ii) identify the time scales over which the Zn species changed, and (iii) elucidate the temporal evolution of the $\mathrm{ZnO}$ surfaces, particle morphology, and size and formation of daughter 
particles. Reacting nanoparticles were imaged in hydrated environments to generate mechanistic insights into the underlying pathways both for environmental damage and potential (de)activation of ZnO ENMs used in consumer products over short-time scales, as they transport through the urban WWTPs.

\section{Results}

ZnO Nanorod Characterization

Scanning electron microscopy (SEM) analysis of the initial nanorod material revealed star-like arrays of $\mathrm{ZnO}$ rods on the silicon nitride windows. Rods exhibited a typical length of $724 \pm 53$ $\mathrm{nm}$ and diameter of $139 \pm 23 \mathrm{~nm}(n=102)$ (Figure 1a). These diameters $(39,40)$ were selected to ensure that the $\mathrm{ZnO}$ nanorods could be detected under hydrated conditions by XFM, meeting the resolution of the hard X-ray nanoprobe capability on the $I 14$ beamline (Diamond Light Source). Energy-dispersive X-ray spectroscopy (EDX) was performed on both the rods and silicon nitride window surface, to confirm their chemical composition (Figure 1b). Complementary X-ray photoelectron spectroscopy (XPS) analyses determined the surface chemistry of the $\mathrm{ZnO}$ nanorods, confirming that sulfates/sulfides and phosphates were absent in the "as-synthesized" structures (Figure 1c). Further details of the $\mathrm{ZnO}$ synthesis and their diameter distribution are presented in the Supporting Information (Figure S1). 
Figure 1
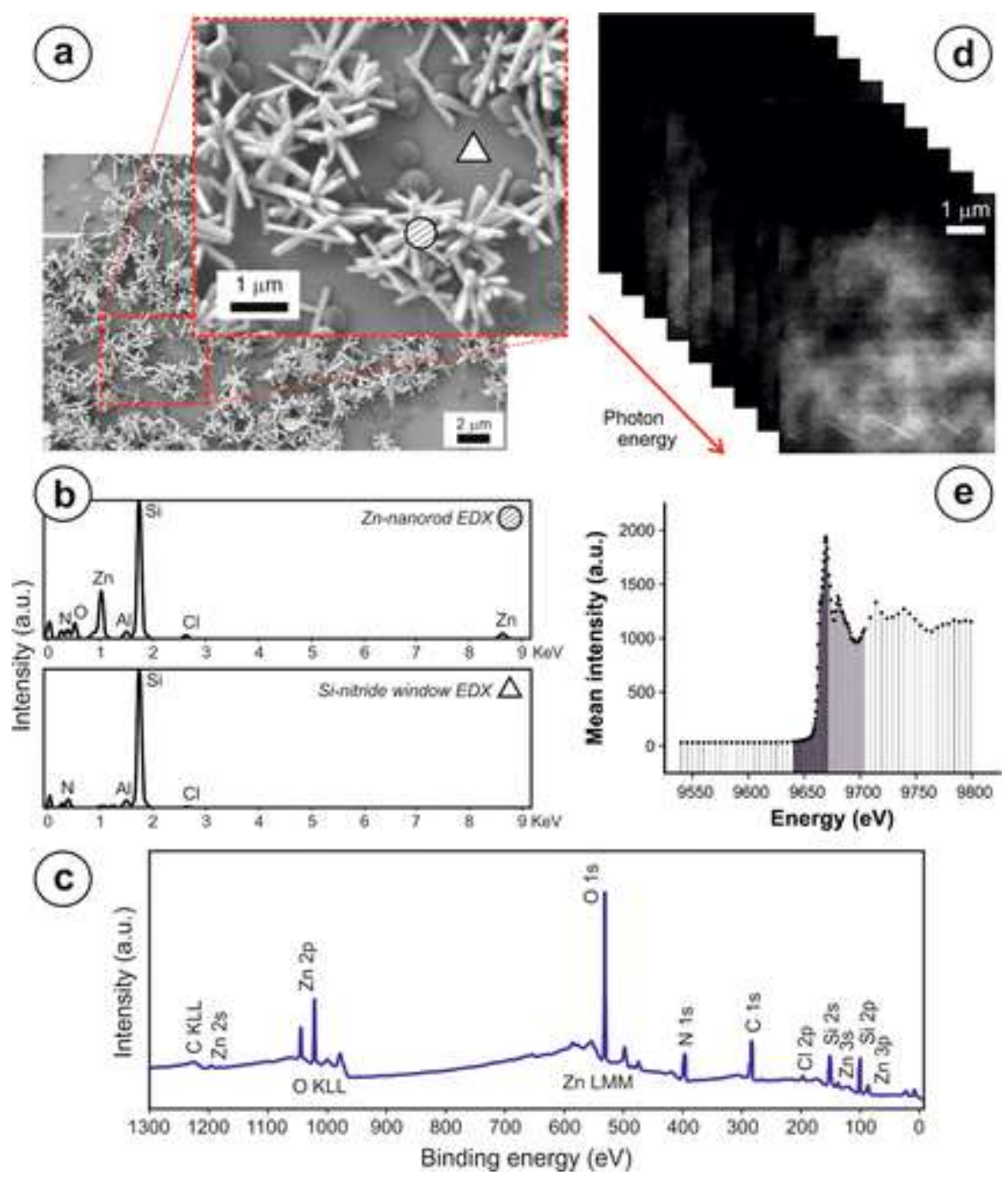

Figure 1. Characterization of the synthesized ZnO nanorods. (a) SEM image of the "assynthesized" ZnO nanorods grown in the silicon nitride membranes. The boxed region shows the higher magnification area selected for EDX analysis. (b) EDX spectra taken from the nanorods (circle) and the silicon nitride (open triangle, Figure 1a). (c) XPS spectrum acquired from the $\mathrm{ZnO}$ nanorods, indicating the presence of zinc and oxygen. (d) A stack of nine X-ray fluorescence microscopy images of the "as-synthesized" ZnO nanorods acquired at 9648.5, 9653, 9658, 9669, 9670.5, 9674, 9675, 9682, and $9702 \mathrm{eV}$ (see further details in Experimental Methods section). (e) XANES spectrum calculated using the mean intensity of 135 energy images acquired along the $\mathrm{Zn} \mathrm{K}$-edge for the "as-synthesized" $\mathrm{ZnO}$ nanorods (as detailed in the Experimental Methods section).

Spatially Resolved Mapping of ZnO Dissolution and Evolution of Morphology As a Function of Time

During incubation of the $\mathrm{ZnO}$ nanorods in a simulated primary sludge environment, consecutive spatially resolved XFM maps were acquired to investigate the morphological evolution of the nanorods over $3 \mathrm{~h}$. Primary sludge is one of the first physio-chemical barriers that influent or sewage waters encounter when entering the cleaning cycle of a regular WWTP. $(2,41)$ This 
sludge is primarily formed by organic matter and humic substances, and hence we selected humic acid as a relevant aqueous component of wastewater sludge. A total of four fluorescence maps were acquired during a $1 \mathrm{~h}$ incubation period (humic acid $10 \mathrm{mg} \mathrm{L}^{-1}$ concentration, $\sim 10$ $\mathrm{min} / \mathrm{map}, 5 \mathrm{~min}$ dead-time between measurements), and 18 maps were collected over the 3 $\mathrm{h}$ in situ incubation period ( $7 \mathrm{~min} / \mathrm{map}, 3 \mathrm{~min}$ dead-time). The consecutive maps were integrated into a single two-dimensional (2D) matrix, where the average $\mathrm{Zn}$ intensity was plotted as a function of time (Figure 2). A slight decrease in the Zn intensity was observed during the first hour of incubation in the simulated sludge (Figure 2a), corresponding to a minor decrease in intensity between the first (left) and last (right) fluorescence maps acquired. Over 3 $\mathrm{h}$ in situ, the $\mathrm{Zn}$ "hotspot" being monitored decreased gradually in size, until it is no longer detectable after $150 \mathrm{~min}$ incubation time (as shown in the first (left) and last (right) XFM maps in Figure $2 \mathrm{~b}$ ). An irregular fluctuation of the $\mathrm{Zn}$ intensity was recorded during the $3 \mathrm{~h}$ in situ experiment (Figure $2 \mathrm{~b}$ ). This can be explained by flux within the medium having an influence on the acquired $\mathrm{Zn}$ mean intensity between consecutive images. The expected $\mathrm{ZnO}$ nanorod dissolution favors the release and transport of $\mathrm{Zn}^{2+}$ ions within the sludge solution, generating the diffusion clouds observed during the in situ imaging (Video S1, Supporting Information).

Figure 2
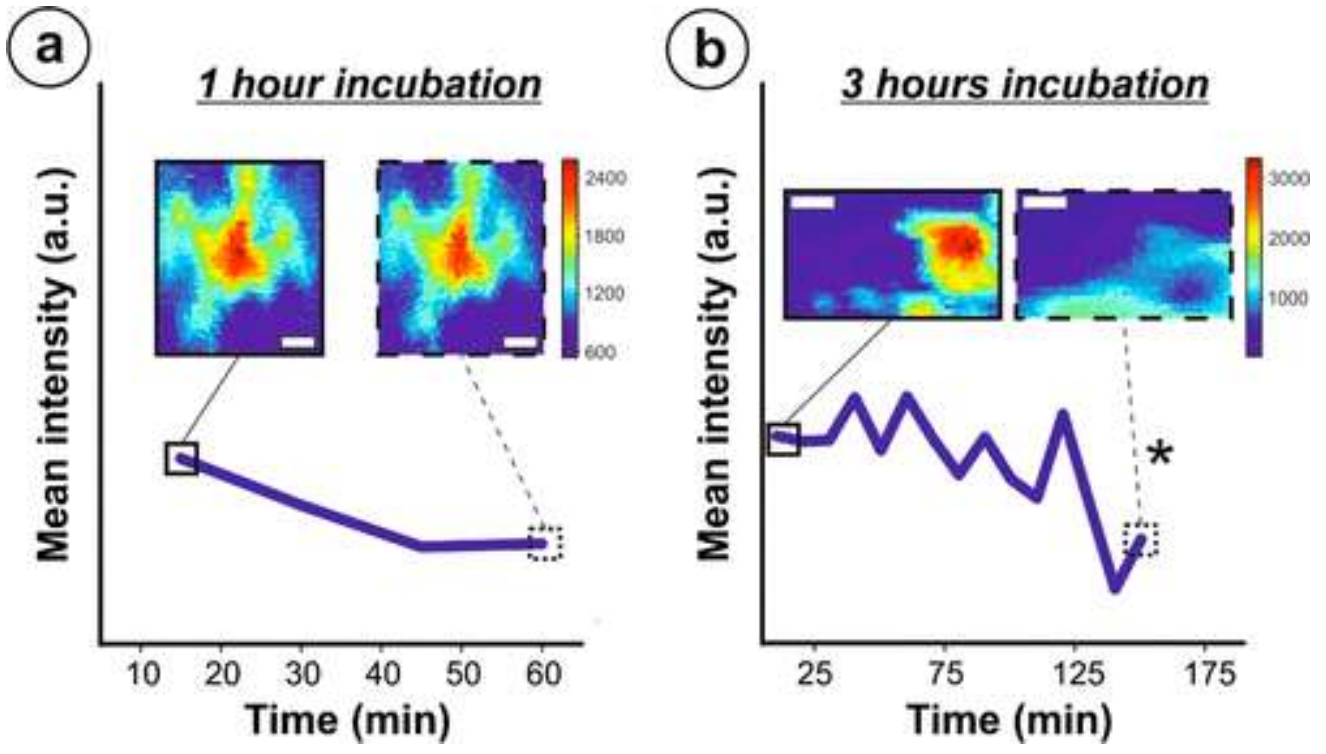

Figure 2. ZnO dissolution as a function of time during the in situ experiments, showing a decrease of $\mathrm{Zn}$ intensity by X-ray fluorescence microscopy. Graphical representation of the $\mathrm{Zn}$ normalized intensity for the acquired XFM maps as a function of the incubation times: (a) $1 \mathrm{~h}$ and (b) $3 \mathrm{~h}$. XFM maps corresponding to the first (left) and the last time map (right, dotted square) are also represented for each condition. Scale bars equal to $750 \mathrm{~nm}$ in all cases. *The variable intensities shown are a consequence of the fluctuating $\mathrm{Zn}$ signal arising from the flux in the internal solution, as presented in the Video S1.

After in situ XFM analyses, the composition of the remaining simulated sludge solutions was quantified by inductively coupled plasma mass spectrometry (ICP-MS), in order to evaluate changes in zinc concentration between 1 and $3 \mathrm{~h}$ (Table1). Iron and phosphorus were also 
quantified since $\mathrm{Zn}_{3}\left(\mathrm{PO}_{4}\right)_{2}$ and $\mathrm{Zn}$ adsorbed to Fe oxy/hydroxides ( $\mathrm{Zn}$-Fe(ox)) are reported to be predominant Zn species in biosolids analyzed after WWTP cleaning processes.(2) The sulfur content could not be quantified due to the limited volume of the sample and its known spectrometric interference with the protons and oxyanions from aquatic media in the ICPMS.(42)

\section{Table 1. ICP-MS Quantification Performed on the Simulated Sludge Solutions Collected after in Situ XFM Analysesa}

ICP-MS quantification ( $\left.\mu \mathrm{g} \mathrm{L}^{-1}\right)$

\begin{tabular}{|c|c|c|c|c|}
\hline in situ solutions & & Zn & $\mathrm{Fe}$ & $P$ \\
\hline \multirow{3}{*}{ simulated sludge } & blank $\underline{b}$ & $9.2 \pm 0.1$ & $102 \pm 1$ & $93 \pm 10$ \\
\hline & $1 \mathrm{~h}$ & $12391 \pm 106$ & $798 \pm 9$ & $264 \pm 20$ \\
\hline & $3 \mathrm{~h}$ & $27533 \pm 216$ & $772 \pm 12$ & $254 \pm 33$ \\
\hline
\end{tabular}

Presented as mean \pm standard error.

The simulated sludge solution (humic acid $10 \mathrm{mg} \mathrm{L}^{-1}$ concentration) used for the in situ experiments was additionally quantified by ICP-MS in order to elucidate the background elemental composition.

The analyses performed by ICP-MS indicate that the $\mathrm{ZnO}$ nanorods begin dissolving within the first hour of exposure to the simulated sludge, releasing $\mathrm{Zn}^{2+}$ ions into the solution (Table1). A significant amount of $\mathrm{Zn}\left(\sim 27.5 \mathrm{mg} \mathrm{L}^{-1}\right)$ was released from the nanorods after $3 \mathrm{~h}$ incubation in the simulated sludge solution, which is in qualitative agreement with the decrease in $\mathrm{Zn}$ intensity measured during the in situ XFM experiment (Figure 2a,b). Phosphorus and iron concentrations were slightly lower after $3 \mathrm{~h}$ compared with the $1 \mathrm{~h}$ incubation in the simulated sludge, possibly indicating that secondary $\mathrm{P}$ - and Fe-rich phases may have precipitated, though the measured variation was not statistically significant (Table1).

Speciation Analyses by Synchrotron-Based Techniques: Zn-Transformations Evaluated by Nine-Energy Scans

Speciation maps were calculated after acquiring nine-energy (9-E) imaging scans, generating a pixel-by-pixel contribution for each Zn species between 0 (dark blue) and 1 (red) (Figure 3 , detailed in the Experimental Methods section). The spectra taken using the 9-E maps for the "as-synthesized" ZnO showed a major ZnO contribution, as expected for both the speciation maps and the quantification maps (SM and QM, Figure 3a). QM were calculated by normalizing the $S M$ to the isosbestic point ( $E_{9}$ in Figure $S 4$ ), producing a visual estimation of the real extent of the $\mathrm{Zn}$ species generation. A fluorescence map was also acquired at the maximum of the $\mathrm{Zn}$ K-edge XANES spectrum ( $E_{\max }=9669 \mathrm{eV}$, [left], 年igure 3) for total Zn intensity contribution. 
Figure 3

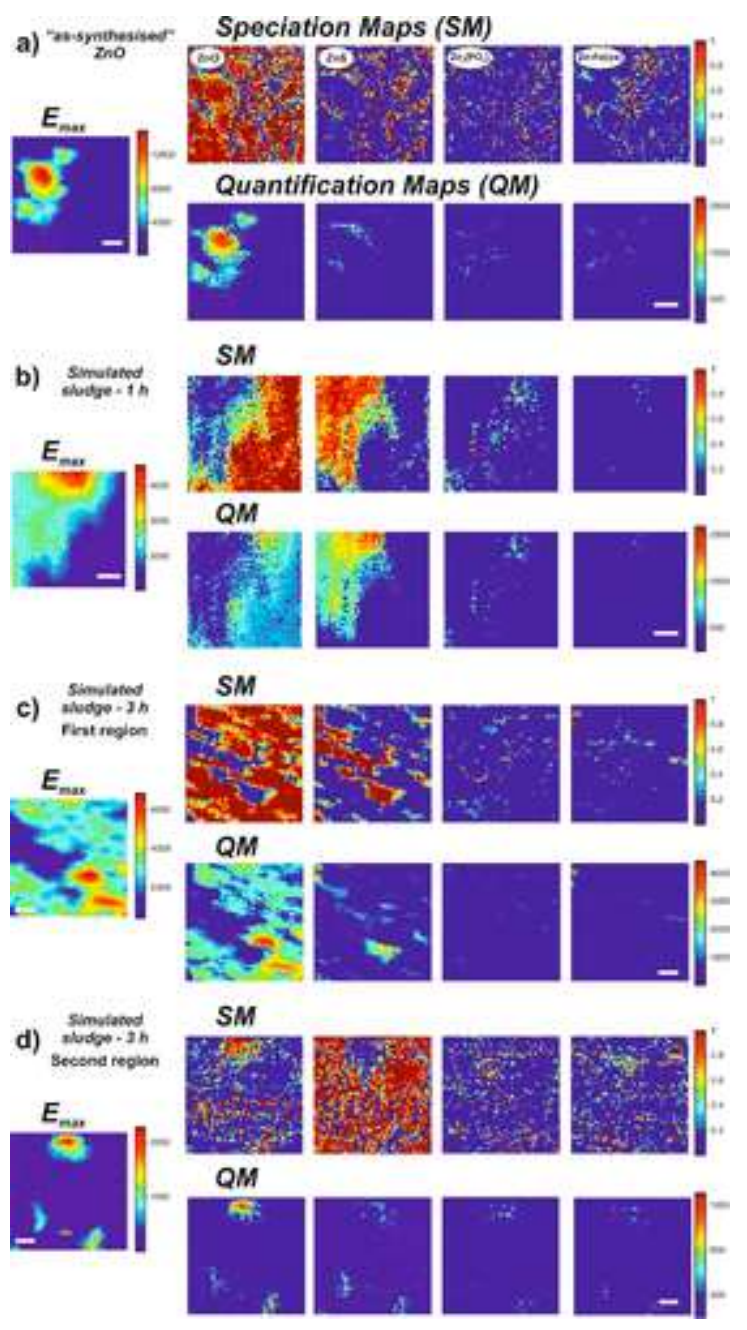

Figure 3. Nine-Energy X-ray fluorescence microscopy of: (a) "as-synthesized" $\mathrm{ZnO}$, (b) sample after the $1 \mathrm{~h}$ incubation in a simulated sludge (humic acid $10 \mathrm{mg} \mathrm{L}^{-1}$ ), and (c,d) two different regions analyzed in the sample after the $3 \mathrm{~h}$ incubation. (Left) Fluorescence map acquired at the maximum of Zn K-edge XANES spectrum ( $E_{\max }=9669 \mathrm{eV}$ ). (Right) SM of the expected Zn species: $\mathrm{ZnO}, \mathrm{ZnS}, \mathrm{Zn}_{3}\left(\mathrm{PO}_{4}\right)_{2}$, and $\mathrm{Zn}$ adsorbed to Fe-oxyhydroxides ( $\mathrm{Zn}$-Fe(ox)) (from left to right), where the red color equals a $100 \%$ compound contribution and the blue color corresponds to $0 \%$ (generated by eq 1). QM for the same species (generated by eq 3) were calculated after normalizing the $S M$ with the isosbestic point $\left(E_{9}\right.$ in Figure $\left.S 4\right)$. The numbering on the scale bars on the QM provides an estimation of the $\mathrm{Zn}$ species contribution. Scale bars equal to $750 \mathrm{~nm}$ in all cases.

After $1 \mathrm{~h}$ incubation of the $\mathrm{ZnO}$ nanorods in the simulated sludge (Figure $3 \mathrm{~b}$ ), $\mathrm{ZnS}$ became the predominant species on the surface of the $\mathrm{Zn}$ hotspot according to the SM. The calculated QM confirmed the prevalence of $\mathrm{ZnS}$ at the top-left location of the $\mathrm{Zn}$ hotspot, although this species does not cover the whole high-intensity region. $\mathrm{ZnO}$ remained as a major phase in this case, both in the top-right location of the spot and in the background of the image. Minor contributions of both $\mathrm{Zn}_{3}\left(\mathrm{PO}_{4}\right)_{2}$ and $\mathrm{Zn}-\mathrm{Fe}(\mathrm{ox})$ in relation to $\mathrm{ZnS}$ were found after $1 \mathrm{~h}$ incubation 
in the simulated sludge solution.

After the $3 \mathrm{~h}$ incubation, different behavior of the $\mathrm{ZnO}$ nanorods was found depending on the region analyzed. In the first region (Figure $3 \mathrm{c}$ ), in the $\mathrm{SM}$, most of the $\mathrm{Zn}$ hotspots remained as $\mathrm{ZnO}$. The quantification maps indicated a significant amount of $\mathrm{ZnS}$ species generated in areas depleted in $\mathrm{ZnO}$. The second region analyzed after $3 \mathrm{~h}$ incubation (Figure $3 \mathrm{~d}$ ) showed a more disperse variation in the $\mathrm{Zn}$ species in the $\mathrm{SM}$, with $\mathrm{ZnS}$ as the dominant species. Although $\mathrm{ZnO}$ was still a major component of the larger hotspots in the $\mathrm{QM}$, there was a significant contribution of $\mathrm{ZnS}$ within the smaller hotspots. Trace amounts of diffuse $\mathrm{Zn}_{3}\left(\mathrm{PO}_{4}\right)_{2}$ and $\mathrm{Zn}$ $\mathrm{Fe}(\mathrm{ox})$ were also mapped after the $3 \mathrm{~h}$ incubation, with different trends in their spatial variations. Compared to the sample incubated in a simulated sludge for $1 \mathrm{~h}$ (Figure $3 \mathrm{~b}$ ), after 3 $\mathrm{h}$, in the first region analyzed, both the $\mathrm{Zn}_{3}\left(\mathrm{PO}_{4}\right)_{2}$ and $\mathrm{Zn}-\mathrm{Fe}(\mathrm{ox})$ contributions decreased in the QM (Figure 3c). Conversely, in the second area analyzed after $3 \mathrm{~h}$ incubation (Figure 3d), the concentration of both species increased in the QM compared to the $1 \mathrm{~h}$ time point, and their distribution became highly diffuse. In region 2 , both $\mathrm{Zn}_{3}\left(\mathrm{PO}_{4}\right)_{2}$ and $\mathrm{Zn}-\mathrm{Fe}(\mathrm{ox})$, as well as the $\mathrm{ZnS}$, were more prevalent within larger $\mathrm{Zn}$ hotspots (refer to the fluorescence map acquired at $E_{\max }$, Figure $3 \mathrm{~d}$, left).

Zn Transformations Evaluated by 135-Energy Scans

To confirm the validity of the spectra extracted from 9-E speciation, a higher energy resolution image stack was acquired using 135-energies (135-E) along the Zn K-edge (see energy-range description in Section S4b, Supporting Information). The mean intensity of the 135-E image stack was measured and represented as a function of energy, generating a "traditional" X-ray absorption near edge spectroscopy (XANES) spectrum for each sample (Figure 1e). These XANES spectra were compared with the $\mathrm{Zn}$-standards in both the $k$-space and the Fourier transform representations (Figure S6). A region of interest, selected from the $k$-space representation, was subsequently analyzed by linear combination fitting (LCF) (Figure 4b). 
Figure 4
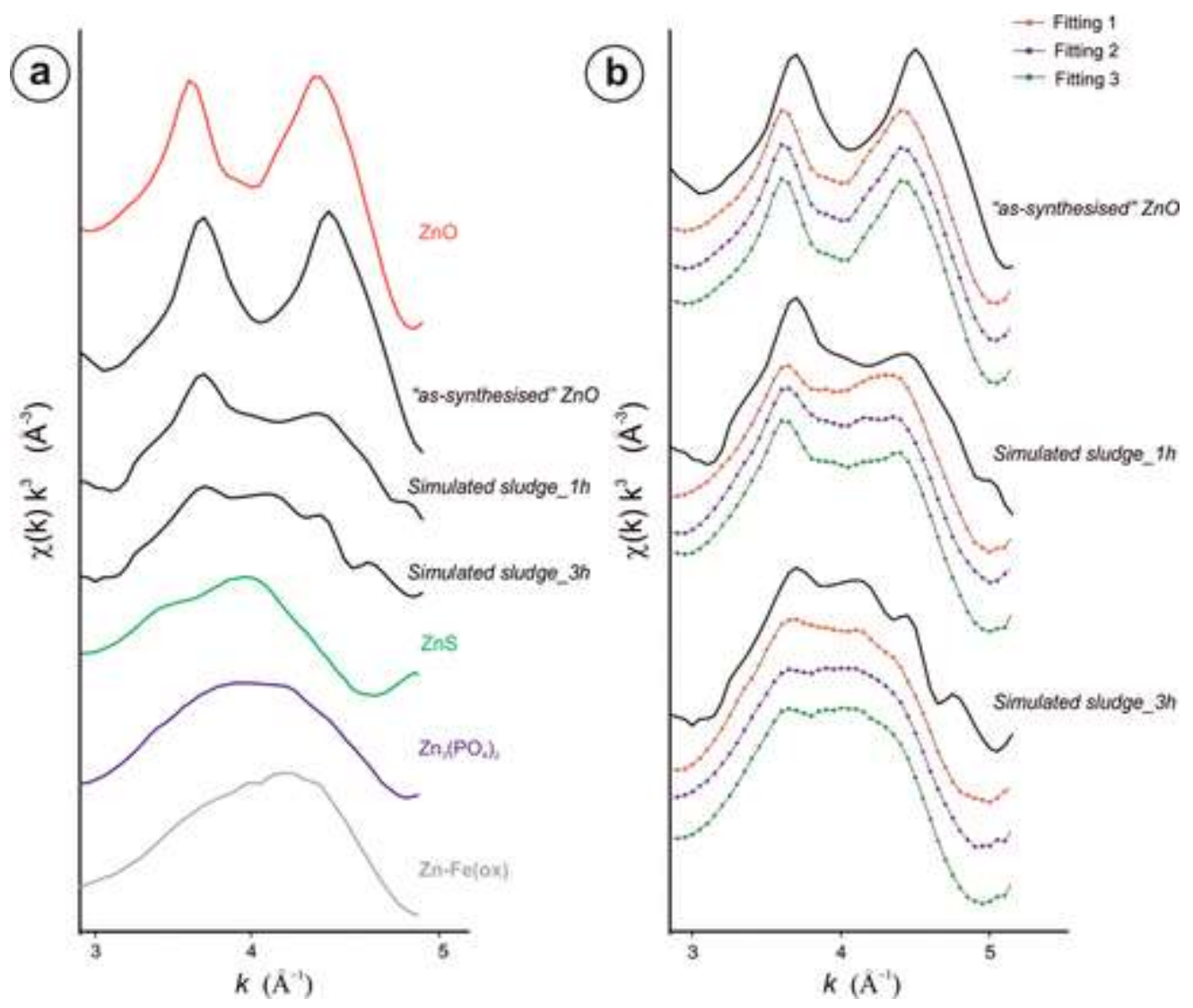

Figure 4. X-ray absorption near edge structure spectra comparison of both samples and standards; and LCF analyses. (a) Focused $k$-space $\left(3-5 \AA^{-1}\right)$ of the $k^{3}$-weighted XANES spectra plotted after 135-E acquisition for the Zn-standards, the "as-synthesized" nanorods, and the samples after in situ incubation in the simulated sludge (humic acid $10 \mathrm{mg} \mathrm{L}^{-1}$ ) solution: $1 \mathrm{~h}$ and $3 \mathrm{~h}$ (second-region, see Figure $3 \mathrm{~d}$ ). (b) LCF of the XANES spectra for the indicated samples, showing the best three fits calculated by Athena software. The LCF values for fits number 1 (red dots), 2 (blue dots), and 3 (green dots) of each sample are presented in Table2.

Comparison of the narrowed $k$-space region $\left(3-5 \AA^{-1}\right)$ from the samples with the standards showed a transition from the $\mathrm{ZnO}$ features (two peaks, red spectrum) to other $\mathrm{Zn}$ species, which presented only a single peak approximately in the middle of the $k$ region (Figure $4 a$ ), when going from the "as-synthesized" sample to the two simulated sludge incubations. An estimation of the sample composition was performed by applying LCF over the $k$-space region (Figure 4b and Table2). The LCF values of the "as-synthesized" ZnO showed a major ZnO contribution in all fittings (ranging 78-86\%) with minor contributions of $\mathrm{ZnS}, \mathrm{Zn}_{3}\left(\mathrm{PO}_{4}\right)_{2}$, and $\mathrm{Zn}$ Fe(ox) (Figure 4b, Table2). LCF data indicated a decrease in the ZnO contribution after only $1 \mathrm{~h}$ incubation in the simulated sludge (to 27-41\%) (Table2). In this case, the best fitting statistical parameters (R-factor and red $\chi^{2}$ ) were found for the $\mathrm{Zn}_{3}\left(\mathrm{PO}_{4}\right)_{2}$ as major species (Table2), although the graphical representation of the LCF indicated that both ZnS and Zn-Fe(ox) could also explain the sample features (Figure 4b). The accuracy of LCF results is generally limited by the accuracy of the standards in representing the chemical species present in the sample and the uniqueness of XANES spectral features between standards.(43) In any case, the LCF results 
shown here can be used to complement the data obtained after the 9-E speciation study.

Table 2. Linear Combination Fit Results for Zn K-Edge XANES Spectra Acquired on Samples before and after in Situ Incubation in the Simulated Sludge Solution

\begin{tabular}{|c|c|c|c|c|c|c|}
\hline fit numbera & $\mathrm{ZnO}(\%) \underline{\mathbf{b}}$ & ZnS (\%)믐 & $\mathrm{Zn}_{3}\left(\mathrm{PO}_{4}\right)_{2}(\%) \underline{\mathbf{b}}$ & $\mathrm{Zn}-\mathrm{Fe}(\mathrm{ox})(\%) \underline{\mathbf{b}}$ & $R$ factor $\underline{c}$ & $\operatorname{red} \chi^{2} \underline{\mathbf{d}}$ \\
\hline \multicolumn{7}{|c|}{ "As-Synthesized" Zno } \\
\hline 1 & 78.0 & & & 22.0 & 0.3022 & 4.728 \\
\hline 2 & 79.6 & & 20.4 & & 0.3027 & 4.737 \\
\hline 3 & 86.6 & 13.4 & & & 0.3188 & 4.989 \\
\hline
\end{tabular}

After $1 \mathrm{~h}$ in Situ Incubation in the Simulated Sludge

\begin{tabular}{|c|c|c|c|c|c|}
\hline 1 & 29.7 & 70.3 & & 0.1413 & 0.9937 \\
\hline 2 & 26.8 & & 73.2 & 0.1959 & 1.378 \\
\hline 3 & 41.5 & 58.5 & & 0.2201 & 1.548 \\
\hline
\end{tabular}

After $3 \mathrm{~h}$ in Situ Incubation in the Simulated Sludge

\begin{tabular}{lcccccc}
\hline 1 & 12.0 & & 81.4 & 6.6 & 0.0856 & 0.5601 \\
\hline 2 & 12.5 & 27.3 & & 60.3 & 0.1177 & 0.7705 \\
\hline 3 & 17.3 & 47.6 & & 35.0 & 0.1553 & 1.017 \\
\hline
\end{tabular}

Linear combination fit was applied over the $k$-range: $3-5 \AA^{-1}$ on the Zn K-edge XANES spectra. The graphical representation of fitting numbers 1 (red dots), 2 (blue dots), and 3 (green dots) is presented in Figure 4.

The contribution of each $\mathrm{Zn}$ species is presented as a percentage. Fittings were constrained to fit $100 \%$.

Normalized sum of the squared residuals of the fit $\left[R=\sum(\text { data }-\mathrm{fit})^{2} / \sum\right.$ data $\left.\left.^{2}\right)\right]$. 
Goodness-of-fit between different fittings was assessed by the $\chi^{2}$ parameter [ $=N_{\text {idp }} / N_{\text {pts }} \Sigma(($ data -

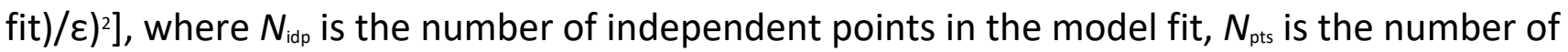
data points, and $\varepsilon$ is the measurement uncertainty.

Finally, a three-standard linear combination fitting was used in the sample incubation for $3 \mathrm{~h}$ in the simulated sludge, indicating a greater mixture of $\mathrm{Zn}$ species. The graphical representation of the LCF does not fit perfectly with the XANES spectrum (Figure 4b), possibly due to the generation of additional species different from the $\mathrm{Zn}$ standards used for the analysis. However, the $\mathrm{ZnO}$ contribution decreased significantly in all fittings when compared with the 1 $\mathrm{h}$ in situ incubation, to a $12-17 \%$ of the total $\mathrm{Zn}$ content (Table2).

Additional Analyses on Residual solids: SEM and XFM

SEM images were acquired on the samples after in situ incubation in the simulated sludge solution (Figure 5 , after draining excess liquid). After $1 \mathrm{~h}$ incubation, most of the $\mathrm{ZnO}$ nanorods showed evidence of partial dissolution, exhibiting thinner rod structures of $164 \pm 21 \mathrm{~nm}$ length and $18 \pm 4 \mathrm{~nm}$ width ( $n=30$, Figure $5 \mathrm{a}$ ). The rods had a hexagonal morphology after $3 \mathrm{~h}$ incubation, with a range of diameters between 200 and $390 \mathrm{~nm}$ ( $300 \pm 48 \mathrm{~nm}$ average) and 439 $\pm 50 \mathrm{~nm}$ length ( $n=30$, Figure $5 \mathrm{~b})$. In both incubation times (1-3 h), residual ZnO nanorods with their original sizes and morphologies were found (positions 1 and 5Figure 5a; positions 6 and 7, Figure $5 b$ ).

Figure 5

(a) 1-hour in situ incubation
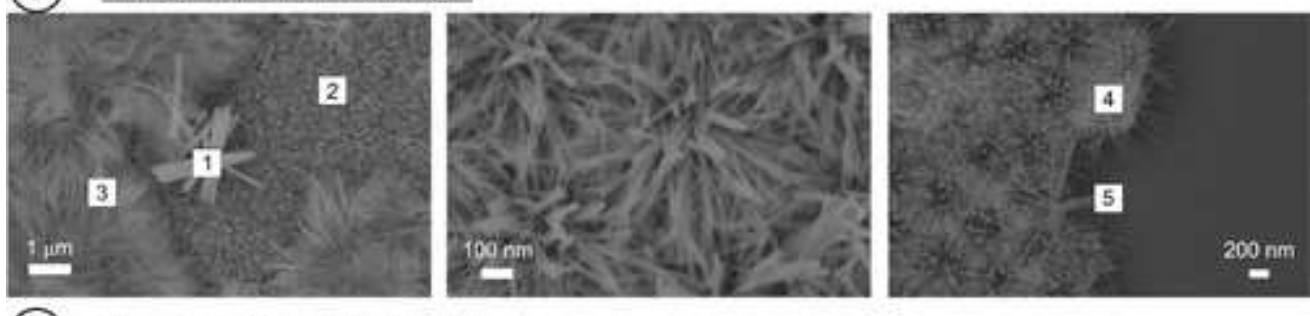

(b) 3-hours in situ incubation
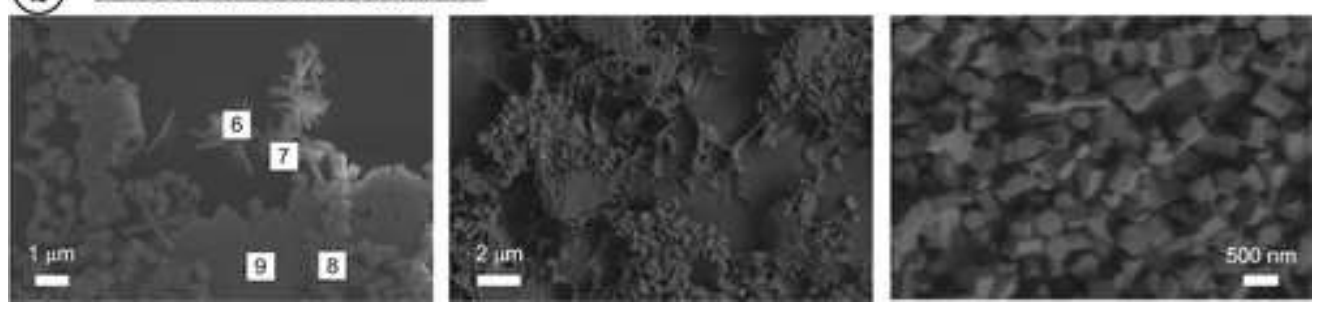

Figure 5. Morphology changes and chemical phases of transformed $\mathrm{ZnO}$ nanorods after in situ incubation in a simulated sludge (10 $\mathrm{mg} \mathrm{L}^{-1}$ humic acid). SEM images acquired after the in situ: (a) $1 \mathrm{~h}$ and (b) $3 \mathrm{~h}$ incubations. Numbers 1-9 represent the locations analyzed by energydispersive X-ray spectroscopy (raw EDX spectra and atomic percentages are shown in Figure $\underline{\text { S2 }}$ and Table S1).

EDX spectra were also acquired from some of the imaged regions (Figure $5 \mathrm{a}, \mathrm{b}$ ), and the atomic percentages are presented in Figure S2 and Table S1. The thinner rods obtained after $1 \mathrm{~h}$ incubation (position 2, Figure $5 \mathrm{a}$ ) had a comparable $\mathrm{Zn} / \mathrm{O}$ ratio to the unreacted original $\mathrm{ZnO}$ 
rods (position 1, Figure 5a), although these values were considerably larger than the "assynthesized" ZnO nanorods ( $\mathrm{Zn} / \mathrm{O}$ ratio $=0.36$, Table S1, Figure 1b). However, the $\mathrm{Zn} / \mathrm{C}$ ratio decreased significantly from the "unreacted" rods to the thinner rods generated during $1 \mathrm{~h}$ incubation in the simulated sludge solution (Table S1). This tendency changed as a function of time since the hexagon-shaped structures formed after $3 \mathrm{~h}$ incubation (position 9, Figure $5 \mathrm{~b}$ ) presented a much higher $\mathrm{Zn} / \mathrm{C}$ ratio than the unreacted $\mathrm{ZnO}$ rods (positions 6 and 7 , Figure $5 \mathrm{~b}$ ). Negligible concentrations of both sulfur and phosphorus were detected by EDX after $1 \mathrm{~h}$ incubation in all locations, according to the calculated standard deviations (RSD, Table S1). Nonetheless, minor sulfur contributions were obtained after the $3 \mathrm{~h}$ incubation in the simulated sludge, both for the unreacted $\mathrm{ZnO}$ rods ( position 7 , Figure $5 \mathrm{~b}$ ) and the nano hexagon-shaped structures (position 8, Figure 5b). Even though EDX is not sufficiently sensitive to detect minor contributions from these elements, (44) SEM-EDX analyses (Figure S2, ESI) indicated ZnO speciation changes toward $\mathrm{ZnS}$ species after $3 \mathrm{~h}$ incubation in a simplified primary sludge medium.

Finally, XFM maps were acquired over larger Zn hotspot areas (igure 6a), already analyzed by the 9-E speciation studies. Figure $6 \mathrm{~b}$ shows a decrease in the mean $\mathrm{Zn}$ signal intensity from the recovered sample after the $1 \mathrm{~h}$ in situ incubation in a simulated sludge compared to the dry ("as-synthesized") sample. This decrease was coupled with a slight increase in both S and $\mathrm{P}$ intensities. Note that it was not possible to perform the XFM analyses on the same drained region as the original $\mathrm{Zn}$ hotspot as the $\mathrm{ZnO}$ dissolved during acquisition (Video S1).

Figure 6
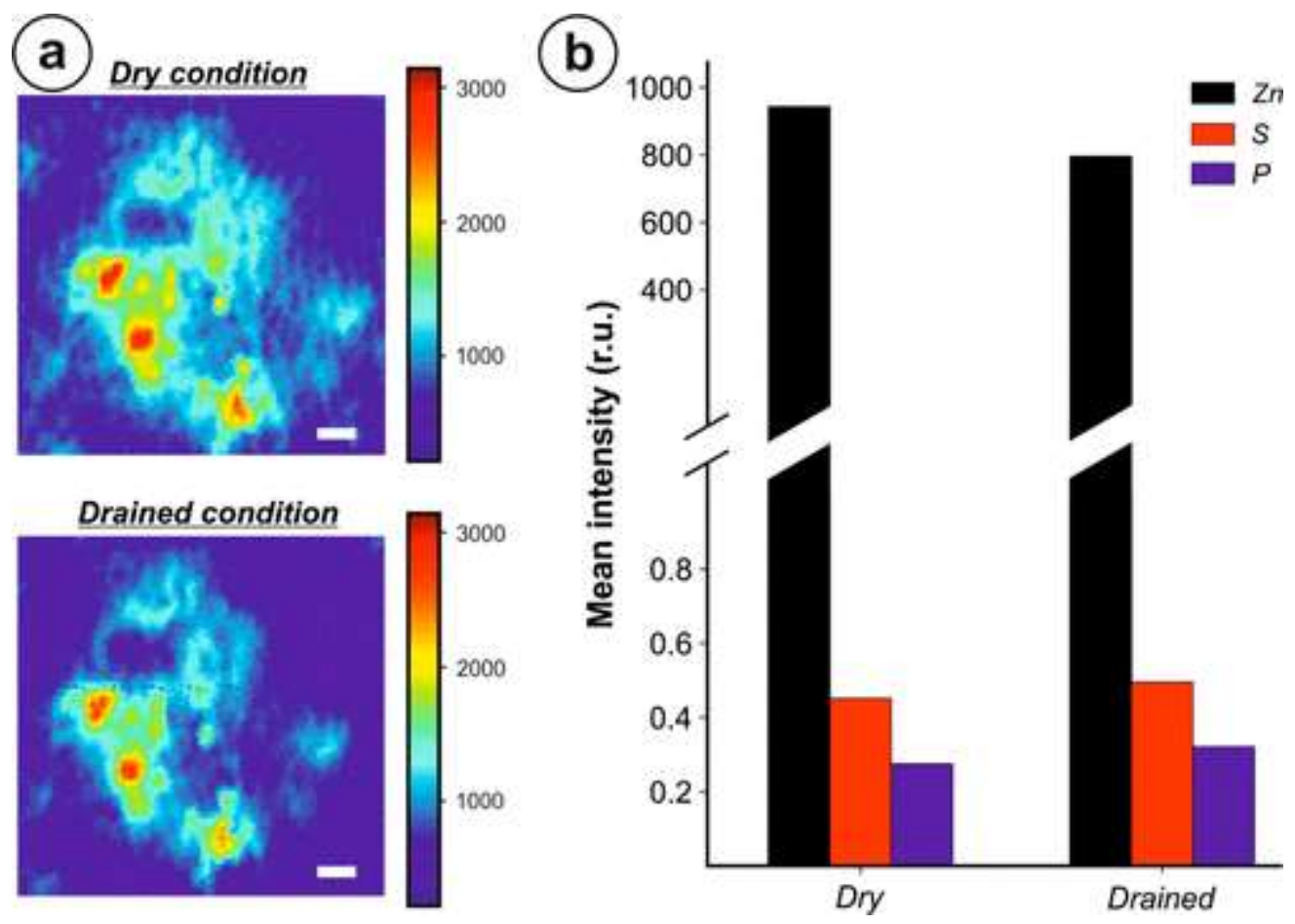

Figure 6. ZnO nanorod transformations measured by X-ray fluorescence microscopy. (a) XFM images acquired from $\mathrm{ZnO}$ nanorods on dry and drained conditions, before and after the $1 \mathrm{~h}$ in situ incubation in the simulated sludge ( $10 \mathrm{mg} \mathrm{L}^{-1}$ humic acid). The numbering on the scale bars represents the maximum intensity measured by XFM. Scale bars equal to $750 \mathrm{~nm}$ in both cases. 
(b) The calculated mean intensity of zinc (black), sulfur (red), and phosphorus (blue) of the previous XFM images.

\section{Discussion}

Using complementary techniques, we have studied the evolution of $\mathrm{ZnO}$ nanorod surfaces, morphology, and chemical transformations during short-term in situ incubations in a simplified simulated wastewater environment. We collected spatially resolved XFM maps in real time to monitor the chemical transformations of the $\mathrm{ZnO}$ nanorods in a simulated primary sludge, composed of humic acid $10 \mathrm{mg} \mathrm{L}^{-1}$ solution at $\mathrm{pH}$ 4.5. It was observed that $\mathrm{ZnS}$ species were the predominantly forming compounds within the studied incubation times (1-3 h, Figure 3 ), which was confirmed by the incremental increase recorded in sulfur intensity measured by ex situ XFM analysis (Figure 6b) after an only $1 \mathrm{~h}$ incubation. Ma et al.(16) studied nano-ZnO transformations in a sulfur-rich environment; in this work, the authors found sphalerite (ZnS) nanoshell formation on the surface of $\mathrm{ZnO}$ nanomaterials. This $\mathrm{ZnS}$ shell did not completely prevent further $\mathrm{ZnO}$ dissolution to $\mathrm{Zn}^{2+}$, and a dissolution and reprecipitation process was suggested to explain the sulfidation of $\mathrm{ZnO}$ nanoparticles. We propose that a superficial $\mathrm{ZnS}$ nanoshell may be generated in our experiment within $1 \mathrm{~h}$ of incubation in a simulated wastewater environment, as shown by the $\mathrm{ZnS}$ diffuse cloud arising from the $\mathrm{ZnO}$ hotspot in Figure $3 \mathrm{~b}$. The potential $\mathrm{ZnS}$ shell formation on the $\mathrm{ZnO}$ core has been reported to dramatically decrease subsequent $\mathrm{Zn}^{2+}$ release from $\mathrm{ZnO}$ nanomaterials, which will be more effective if higher degrees of sulfidation are achieved.

Nonetheless, a full transformation of $\mathrm{ZnO}$ was not observed here over the short-time scales studied (1-3 h), evidenced by the decreased, but nonzero, $\mathrm{ZnO}$ contribution as a function of time calculated by LCF of the XANES spectra generated after the 135-E speciation analyses (Figure 4, Table2). Compared to the precursor $\mathrm{ZnO}$ nanorods, the partial formation of less soluble (and potentially less bioreactive) ZnS phases in wastewater environments may have both direct and indirect impacts to microorganisms. Using a metagenomic approach to characterize the bacterial microbiome in activated sludge, Meli et al.(6) recorded a concentration-dependent reduction in the number of operational taxonomic units (OTU's) following the application of $\mathrm{ZnO}$ nanoparticles (NPs). Though speciation was not measured in that work it is likely that transformations would have occurred. Such negative impacts on microbial populations could seriously impact their vital role as bioremediators, reducing the nutrient concentrations of effluents. Furthermore, primary sludge, containing variously transformed Zn species may subsequently be applied to land as fertilizers, through biosolids generation during the anaerobic digestion.(15) Durenkamp et al.(8) found minimal impacts to the composition and functioning of soil bacteria growing in soil amended with WWTP sludge containing silver and zinc oxide nanoparticles compared with metals salt equivalents, though a reduction in fungi was recorded following metal exposure. However, they did not measure if transformations occurred in $\mathrm{Zn}$ forms once the sewage sludge was added to the soil. Short-term negative impacts to biota following the application of pristine ENMs to soils have not been taken into account, leading to erroneous assessments of the toxicity of ENMs.(8) Here we demonstrate that particle modification can occur over relatively short time scales, hence 
impacts measured in the very short-term may not necessarily be realized in the long term, illustrating the highly dynamic nature of ENMs modification. The tendency for aggregation is increased in ZnS particles,(16) which may promote sedimentation not only in WWTPs but also in the natural environment. Once deposited in benthic regions, for example, river beds, ENMs may be exposed to extreme gradients in $\mathrm{pH}, \mathrm{H}_{2} \mathrm{~S}$, and redox conditions, which are likely to further influence transformation, affecting their toxicity.(6) With modifications, the proposed XFM detection and speciation methodology can be further utilized as a test bed to analyze ENMs impacts in aquatic media, over a suite of environmental regimes.

Our results also suggest the presence of daughter particles of both $\mathrm{Zn}_{3}\left(\mathrm{PO}_{4}\right)_{2}$ and $\mathrm{Zn}$ adsorbed to Fe-oxyhydroxides after the short-time in situ incubations in a simulated primary sludge, by traditional linear combination fitting of the $\mathrm{Zn}$-standards spectra (Figure $4 \mathrm{~b}$, Table2) and X-ray fluorescence microscopy (Figure 6b). The formation of a $\mathrm{ZnO}-\mathrm{Zn}_{3}\left(\mathrm{PO}_{4}\right)_{2}$ core-shell structure has been reported in phosphate-rich environments,(45) where $\mathrm{Zn}^{2+}$ can be complexed with aqueous $\mathrm{PO}_{4}{ }^{3-}$, resulting in the formation of an amorphous zinc phosphate hydrate precipitate.(46) Although $\mathrm{Zn}_{3}\left(\mathrm{PO}_{4}\right)_{2}$ is the thermodynamically favored species, the full transformation to these species is kinetically limited to longer reaction times (15 days),(45,46) which were not studied here. The higher solubility reported by Ma et al.(16) for the $\mathrm{ZnS}$-shell/ZnO nanomaterials than that expected for bulk $\mathrm{ZnS}\left(K_{\mathrm{sp}}=2 \times 10^{-25}\right.$ yields a solubility of $3.7 \times 10^{-10} \mathrm{mM}$ ) would kinetically favor the transformation to $\mathrm{ZnS}$ phase rather than to $\mathrm{Zn}_{3}\left(\mathrm{PO}_{4}\right)_{2}$. This fact was confirmed by ex situ SEM-EDX analyses after $3 \mathrm{~h}$ incubation (positions 6 and 7, Figure 5b, Table S1), highlighting the importance of the Zn-sulfide over the Znphosphate phases. Complementary XAS analyses were conducted on commercial smaller $\mathrm{ZnO}$ nanoparticles (10-30 $\mathrm{nm}$ size) incubated for $3 \mathrm{~h}$ in the simulated sludge solution (Figure S5). These results showed a transition on the maximum of peak for the three samples incubated in humic acid toward lower energy-values from the $\mathrm{ZnO}$ (red) to the $\mathrm{ZnS}$ (green) and $\mathrm{Zn}_{3}\left(\mathrm{PO}_{4}\right)_{2}$ species (blue) (Figure S5a, yellow arrow), confirming that $\mathrm{ZnO}$ nanoparticles in solution will transform into the same phases as the fixed $\mathrm{ZnO}$ nanorods, which validates the use of the methodology presented in this work.

However, stability diagrams for the $\mathrm{Zn}$-S-P system indicate that $\mathrm{Zn}_{3}\left(\mathrm{PO}_{4}\right)_{2}$ should be a stable product under oxidizing conditions.(16) Le Bars et al.(47) showed that nano-ZnS is a major Zn species in raw liquid organic wastes, but only a minor species in solid and more processed organic-rich wastes. In this case, most of the $\mathrm{Zn}$ phases transformed to either amorphous $\mathrm{Zn}$ phosphate or $\mathrm{Zn}$ adsorbed to ferrihydrite in composts. A similar tendency has been reported in the biosolids formation at a pilot WWTP,(15) where the ZnS transformed mostly to $\mathrm{Zn}_{3}\left(\mathrm{PO}_{4}\right)_{2}$ after the anaerobic digestion process. The formation of $\mathrm{Zn}_{3}\left(\mathrm{PO}_{4}\right)_{2}$ species after secondary and tertiary wastewater treatment process would have potential environmental implications since their eco-toxicity to algae/bacteria would inherently change.

The presence of humic acid, used as simplified primary sludge during the in situ incubation, also has an influence on the $\mathrm{ZnO}$ nanorod behavior, by affecting the mechanisms in which the organic molecules interact with particle surfaces.(48) Natural organic compounds (i.e., humic/fulvic acids) in aqueous environments may be adsorbed onto nanomaterial surfaces, $(49)$ generating bridges between the nanomaterials and the organic molecules via multiple functional groups. Suwannee River humic and fulvic acids have been reported to promote $\mathrm{ZnO}$ nanoparticle dissolution, which increases linearly with their concentration (from 0 to $\left.40 \mathrm{mg} \mathrm{CL}^{-1}\right),(50)$ although inhibition of $\mathrm{ZnO}$ dissolution could result 
from steric protection following humic acid adsorption.(51) Furthermore, the number of $\mathrm{ZnO}$ nanorods per unit area on the initial template and their geometry are thought to play a role in subsequent $\mathrm{ZnO}$ morphology and speciation changes. This would explain why $\mathrm{ZnO}$ transformation to $\mathrm{Zn}_{3}\left(\mathrm{PO}_{4}\right)_{2}$ species was sterically limited in the first region analyzed after $3 \mathrm{~h}$ incubation (SM, Figure $3 \mathrm{c}$ ) in comparison with the more accessible second region (SM, Figure 3d).

An ongoing $\mathrm{ZnO}$ dissolution was monitored by XFM during the in situ experiments, which was also revealed by the increasing $\mathrm{Zn}^{2+}$ concentration in the incubation solutions analyzed by ICPMS (Table1). This process was initially slow but then speeded up rapidly after 130-140 min, in some regions, leading to the complete disappearance of the Zn hotspots (Video S1). This fact added more heterogeneity to the $\mathrm{ZnO}$ transformation, since the more "exposed" nanorods may be dissolved after the $3 \mathrm{~h}$ incubation. This heterogeneity was also observed on the highresolution SEM images acquired (Figure 5), where $\mathrm{ZnO}$ nanorods underwent different compositional and structural changes according to the steric impedance. Our results suggest that at longer time scales (24-48 h), we might expect to see a complete dissolution of all the $\mathrm{ZnO}$ nanorods, with some $\mathrm{Zn}$ being released into solution as $\mathrm{Zn}^{2+}$ and some precipitating/transforming as ZnS particles or core-shell structures.

The acidic $\mathrm{pH}$ conditions tested here (4.5) are expected to promote $\mathrm{ZnO}$ dissolution, by generating soluble ions including $\mathrm{Zn}^{2+}$ and $\mathrm{Zn}(\mathrm{OH})^{+}$.(52) Fast dissolution rates have been reported in different environments such as soils (within only $1 \mathrm{~h})(53)$ and artificial lysosomal fluid at a similar $\mathrm{pH}(54)$ (within $24 \mathrm{~h}$ ). As a consequence, thinner $\mathrm{ZnO}$ nanorods were observed after $1 \mathrm{~h}$ incubation (Figure 5a), while larger hexagon-shaped $\mathrm{ZnO}$ assemblies, with faceting that resembles the Wurtzite crystalline structure, were generated after $3 \mathrm{~h}$ (Figure $5 \mathrm{~b}$ ). Similar hexagon-shaped $\mathrm{ZnO}$ structures have been reported after electrodeposition of $\mathrm{ZnO}$ layers by Illy et al.,(55) who also indicated that acidic pH (below 4.1) can dramatically change the film thickness and the crystallographic orientation of the $\mathrm{ZnO}$.

The methodology described in this work allowed us to recreate "as-synthesized" ZnO nanorod transformations in situ, obtaining significant information within their early stages (1-3 h) of exposure in an environmentally relevant aquatic medium. Differences in the chemistry of real sludges, such as varied $\mathrm{pH}$ and increased phosphate ion concentrations, will alter the composition and morphology of the transformed $\mathrm{ZnO}$ nanomaterials, for example, we would expect to detect more zinc phosphate daughter particles in a real sludge. Here, we show marked changes to the structure and chemistry of these nanomaterials incubated in humic acid solution, in an experimental cell. These results can be extrapolated to wastewater systems containing humic acid as organic matter content, providing insights about the fate and partitioning of $\mathrm{Zn}$ species in two-stage conventional wastewater treatment plants. With modifications, this test-bed can now be utilized to measure impacts of ZnO ENMs in a wide range of environmental scenarios, including real wastewater sludges.

\section{Conclusions}

Here, spatially resolved maps of $\mathrm{ZnO}$ nanomaterial transformation within a simulated environmental medium have been acquired dynamically. Our findings demonstrated: (i) ZnO nanorods partially transformed to $\mathrm{ZnS}$ species predominantly within in situ short-time incubations (1-3 h) in a simulated primary sludge medium; (ii) minor $\mathrm{Zn}_{3}\left(\mathrm{PO}_{4}\right)_{2}$ and $\mathrm{Zn}$ adsorbed 
to Fe-oxyhydroxides were also measured in some nonsterically impeded regions; and (iii) the ongoing $\mathrm{ZnO}$ dissolution and the humic acid presence have an influence in the preferential transformation of the remaining $\mathrm{ZnO}$ nanorods.

Nanomaterials transformations take place rapidly, as highlighted here by the generation of ZnS species after only $1 \mathrm{~h}$ incubation, and these transformations depend on several factors (i.e., $\mathrm{pH}$, elemental composition, temperature, redox conditions, and organic matter content).

Therefore, developing cutting-edge spatially resolved speciation analyses in real time, such as the described 9-E methodology, will illuminate the extent of nanomaterial transformations within relevant aquatic environments at relevant length scales, from the individual particles to micrometric aggregates. This could provide crucial information about the underlying pathways both for environmental damage and (de)activation of engineered nanomaterials used in consumer products and the implications for their passage through natural environments. More generally, this in situ methodology is potentially a widely applicable and powerful means to characterize transformations of nanomaterials within a range of complex hydrated systems, such as natural waters or biological environments (e.g., bacteria, algae, macroinvertebrates, etc.). The XFM could also be utilized to study the kinetics of nanomaterials transformations in situ in a range of related fields, such as nanomedicine and biomineralization. As nanomaterials formulations become more complex, the XFM technique would offer the possibility to characterize chemical transformations of individual nanoparticles within these mixtures and coupled behavior between the particles. When studying the structural and functional impacts of transformed ENMs on organisms, this information could, in the future, be used to generate mechanistically underpinned insight into predict ENM behavior, to refine guidelines for safe use, and to inform remediation strategies of ENMs.

\section{Experimental Methods}

\section{Synthesis and Characterization of ZnO Nanorods}

Reproducible $\mathrm{ZnO}$ nanorod-like arrays were synthesized on silicon nitride windows $(2 \times 2 \mathrm{~mm}$ membrane, $5 \times 5 \mathrm{~mm}$ frame; $1000 \mathrm{~nm}$ thickness; Norcada) following the procedure described by Xie et al.(39) and Wang et al.(40) The experimental steps are described in Figure S1 and summarized as follows: (1) a non-close-packed polystyrene monolayer ( $400 \mathrm{~nm}$ diameter) was formed using a liquid interface-mediated method; (2) a seed layer deposition of $\mathrm{ZnO}$ was applied on the polystyrene monolayer; and (3) a hydrothermal growth of $\mathrm{ZnO}$ nanorod-like arrays was performed onto the seed layer. All chemicals were purchased from Sigma-Aldrich, as

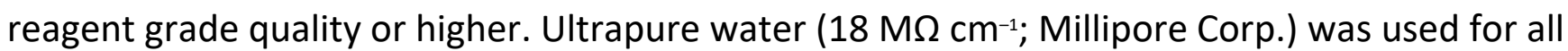
solutions and dilutions.

SEM images of the ZnO nanorod-like arrays were collected using a LEO Gemini 1525 field emission gun scanning electron microscope (FEG-SEM), equipped with a Genesis 4000 EDAX for the collection of EDX spectra of the samples. Samples were sputter coated with a $\sim 5 \mathrm{~nm}$ carbon layer before the SEM-EDX analyses to increase the conductivity of the samples without interfering with the compositional determinations performed by EDX.

The surface chemistry of the $\mathrm{ZnO}$ nanorods was characterized by XPS. The spectra were recorded on a Thermo Scientific K-Alpha+ $X$-ray photoelectron spectrometer (XPS) system (base 
pressure $2 \times 10^{-9} \mathrm{mbar}$ ), incorporating a monochromated, microfocused Al Ka X-ray source ( $h v=$ $1486.6 \mathrm{eV}$ ) and a $180^{\circ}$ double focusing hemispherical analyzer with a 2D detector. The X-ray source was operated at $6 \mathrm{~mA}$ emission current and $12 \mathrm{kV}$ anode bias. Data were collected using a $400 \times 400 \mu \mathrm{m}^{2} \mathrm{X}$-ray spot and a pass energy of $200 \mathrm{eV}$ for the survey and a $20 \mathrm{eV}$ pass energy for core level and valence band spectra, respectively. A flood gun was used to minimize sample charging, and spectra were aligned assuming the $C 1 \mathrm{~s}$ core line to be at a binding energy of $285.0 \mathrm{eV}$. All data were analyzed using the Avantage software package (Thermo Scientific).

\section{Synchrotron X-ray Analyses}

XFM analyses were carried out on the Hard X-ray Nanoprobe at the I14 beamline (Diamond Light Source Ltd., Didcot, UK). X-rays from an undulator source are preshaped using a pair of horizontal mirrors onto a secondary source, with a $\mathrm{Si}(111)$ horizontally deflecting double-crystal monochromator providing monochromatic X-rays, selectable over the energy range 5-23 keV. The beam propagates to an external building (source-sample distance $186 \mathrm{~m}$ ) where it is focused using preshaped KB mirrors. The focused X-ray beam size for this experiment was 150 $\mathrm{nm}$. The sample is raster scanned (continuous scanning) through the $X$-ray focus, and the fluorescent $X$-rays collected by a four-element silicon drift detector (Rayspec) with a solid collection angle of $0.8 \mathrm{sr}$.

In Situ Incubation Experiments: X-ray Fluorescence Microscopy and ICP-MS

An "in-house" liquid cell was designed for the in situ synchrotron XFM analyses, with specifications designed to fit the size and geometry requirements of the 114 beamline at the Diamond Light Source synchrotron facility. This polyhedral aluminum cell $(15 \times 10 \times 6$ $\mathrm{mm}, h \times w \times d)$ ), with an open space of $4 \mathrm{~mm} \times 4 \mathrm{~mm}$ in the beam trajectory (Figure S3a), was mounted in the beamline stage and fixed with a magnetic bottom located at the end of the cylindrical base (Figure S3b). There, the silicon nitride window, with the $\mathrm{ZnO}$ nanorods attached, was placed in the middle of the experimental window, aligned within the path of the $\mathrm{X}$-ray beam, and secured with two Kapton polyimide foils ( $\sim 80 \mu \mathrm{m}$ width). According to the geometry of the cell and in order not to overfill it, a volume of $200 \mu \mathrm{L}$ of synthetic simulated medium was pipetted in for every in situ experiment performed (Figure S3C).

As a simplified simulated primary sludge, a humic acid solution of $10 \mathrm{mg} \mathrm{L}^{-1}$ was selected, presenting a reasonable organic matter concentration for the experimentation, as previously studied by Bian et al.(20) This humic acid stock solution was prepared by dissolving solid humic acid (Sigma-Aldrich) in water for $12 \mathrm{~h}$ under stirring and then filtering the solution through a $0.45 \mu \mathrm{m}$ filter cartridge.(49) Subsequent acidification to $\mathrm{pH} 4.5$ with acetic acid $0.1 \mathrm{M}$ was carried out to simulate the $\mathrm{pH}$ conditions of the real primary sludge. The total organic carbon of the solution was quantified before performing the in situ experiments, accounting for $8.65 \mathrm{mg} \mathrm{C}$ $\mathrm{L}^{-1}$. This parameter was used as an indicator of the organic matter present in the solution regardless of the extent of humic acid solubility, which might be limited.(20) After the addition of $200 \mu \mathrm{L}$ of the simulated sludge solution in the in situ cell, XFM maps (10 $\times$ $10 \mu \mathrm{m}$ or $15 \times 15 \mu \mathrm{m}$ size, $100 \mathrm{~ms}$ acquisition time per pixel, $75 \mathrm{~nm}$ pixel-size) were acquired consecutively at $12 \mathrm{keV}$ during the course of the $1 \mathrm{~h}$ and $3 \mathrm{~h}$ in situ experiments (with a 2 or 5 min dead-time between consecutive measurements, respectively). The acquired XFM maps 
were postprocessed, in order to measure the intensity signal of: $\mathrm{P} \mathrm{K} \alpha, \mathrm{S} \mathrm{K} \alpha, \mathrm{Cl} K \alpha, \mathrm{Ca} K \alpha, \mathrm{Ti} K \alpha$,

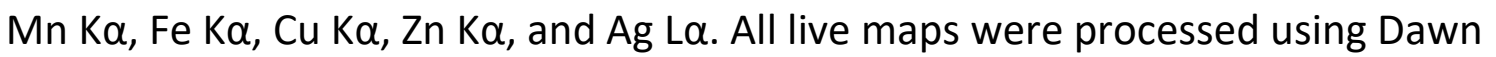
software,(56) generating an individual image for all acquired conditions and reprocessed elements (×10). Each individual map was subsequently integrated using Matlab software, obtaining the average intensity of every element in the XFM map.

These two short-time scales ( $1 \mathrm{~h}$ and $3 \mathrm{~h}$ ) were selected to evaluate the $\mathrm{ZnO}$ nanorod morphology and speciation within the initial stages of their release to aquatic media containing organic matter. To calculate the extent of the $\mathrm{ZnO}$ nanorod dissolution in the simulated sludge, the residual solution was quantified for aqueous $\mathrm{Zn}$ concentration by ICP-MS (PerkinElmer NexION 350D). Upon completion of the in situ experiments, the liquid phase was collected with precleaned syringes, diluted to $2 \mathrm{~mL}$ with ultrapure water acidified to $1 \% \mathrm{HNO}_{3}$ (trace-metal grade), and stored at $4{ }^{\circ} \mathrm{C}$ before analyses.

Speciation Analyses Evaluated by Multi-Energy Scans: Methodology

To obtain chemical and speciation information along the Zn K-edge, XFM image stacks were collected using different photon energies.(57) These images were acquired on the incident photon flux $I_{0}$ to compute reference corrected absorbance images, $-\ln \left(I / I_{0}\right)$. Subsequently, XANES spectra were analyzed pixel-by-pixel and compared to the relevant standard X-ray absorption edges, providing spatially resolved chemical information. Speciation maps (SM) were then calculated through fitting the absorption data from each pixel to the linear combination of the standard (LCS) spectra, as represented by the following (eq 1): $\mathrm{LCS}=w_{1} \mathrm{ZnO}+w_{2} \mathrm{ZnS}+w_{3} \mathrm{Zn}_{3}\left(\mathrm{PO}_{4}\right)_{2}+w_{4} \mathrm{Zn}-\mathrm{Fe}(\mathrm{ox})(1)$ where the least-squares fit weights $\left(w_{i}\right)$ were calculated per pixel (where $\sum w_{i}=1$ ), thus a $2 \mathrm{D}$ plot of $w_{i}$ represents the spatial distribution maps of $\mathrm{Zn}$ species across the particle, defined here as SM.

Therefore, a SM of the sample, representing the ratio between $\mathrm{Zn}$ species could be formed by plotting the different $w_{i}$ maps (as seen in Figure 3 ). Furthermore, the percentage of each species can be quantified by first considering the absorbance intensity of the sample at an isosbestic energy point. The isosbestic point is the incident $\mathrm{X}$-ray energy where the absorption of all $\mathrm{Zn}$ species is equal ( $E_{9}$ in Figure $S 4$ ). Hence, absorbance intensity variations across the imaged sample are proportional to the total amount of $\mathrm{Zn}$ present irrespective of speciation in accordance with the Beer-Lambert law:absorbance $=a(\lambda) \times t \times c(2)$ where $a(\lambda)$ is a wavelengthdependent absorptivity coefficient, $t$ is the $X$-ray path length, and $c$ is the component concentration.

In addition, quantification maps (QM) can be calculated, including the overall amount of each species, in the image through the following calculation ( $\underline{\text { eq 3 3 }): ~}{ }^{\mathrm{QM} \%}=\frac{\sum_{n}\left(P_{n} \times I_{n}\right)}{\sum_{n}(I)} \times 100$ (3) where " $P$ " is the proportion of $\mathrm{Zn}$ species between 0 and 1 in an individual pixel $(n)$, and " $I$ " its absorbance intensity at the isosbestic point).

By applying the same equation to all the relevant $\mathrm{Zn}$ species included in the calculation, the amount of $\mathrm{Zn}$ in an individual pixel was obtained. The percentage calculated with this equation is subsequently (pixel-by-pixel) normalized by the intensity value obtained in the isosbestic point (ninth energy, Figure S4), where the absorbance is related to the total amount of Zn present irrespective of speciation.(57) Hence, the numbering on the scale bars on the QM provides an estimation of the $\mathrm{Zn}$ species contribution. 
Nine different images were collected along the Zn K-edge at nine-energies (9-E) as follows: (i) for background removal, three energies (9648.5, 9653, and $9658 \mathrm{eV}$ ) at Zn pre-edge were acquired; then (ii) five postedge energies (9669, 9670.5, 9674, 9675, and $9682 \mathrm{eV}$ ) were recorded to map different $Z n$ phases; and (iii) a spectrum image was acquired at (9702 eV), defined as the isosbestic point, at which all data were normalized ( $E_{9}$ in Figure $S 4$ ). An example of absorption data obtained from individual pixels across the indicated stack of 9-E is shown in Figure 1d, while all the 9-E image stacks obtained for the samples are included in the Figure S7. The use of only nine absorption energies is a trade-off between accurate chemical analysis versus temporal resolution and X-ray dose (explained in Section S5a, Supporting Information). In order to validate these results, complementary XANES maps were also performed by imaging at 135 different energies along the Zn K-edge (Figure 1e). There, the mean intensity of each individual image was plotted as a function of the energy, generating an individual XANES spectrum which could be analyzed by linear combination fitting using $\mathrm{Zn}$ standards and according to the Zn species previously described in WWTP systems. $(2,58)$ Therefore, bulk ZnO, nano $\mathrm{ZnO}\left(80-200 \mathrm{~nm}\right.$, US nano), ZnS, $\mathrm{Zn}_{3}\left(\mathrm{PO}_{4}\right)_{2}$, and $\mathrm{Zn}$ adsorbed to Fe oxy-hydroxides were used as standards for data analysis (Figure S4).

The $k$-space and the Fourier-transform representations of the XANES spectra of both standards and the samples analyzed in the study are presented in Figure S5 (Section S5, Supporting Information). Linear combination fitting (LCF) of the XANES $k$-region: $3-5 \AA^{-1}$ was performed by Athena from Demeter software,(37) in order to focus in the distinctive features on this region. The background was subtracted by using a linear fit through the $\mathrm{Zn}$ pre-edge region and the autobk routine in Athena for the spline fit through the XANES region. The LCF of the Zn spectra was carried out starting from the best fit with one component, and the number of components $n$ was increased as long as the normalized sum of the squared residuals (NSSR = $\left.\sum\left(\text { data }_{\mathrm{i}}-\mathrm{fit}_{\mathrm{i}}\right)^{2} / \sum\left(\text { data }_{\mathrm{i}}\right)^{2}\right)$ of best $n+1$ - component fit was at least $10 \%$ lower than the NSSR of the best $n$ - component fit and if no component accounted for $<5 \%$ of total $\mathrm{Zn}$. More details about the methodology followed in this study are shown in the Supporting Information (Section $\underline{\mathrm{S}}$ ), including an evaluation of the accuracy of the 9-E speciation analyses (Section S5c).

Complementary XAS analyses were conducted on commercial smaller ZnO nanoparticles (10-30 $\mathrm{nm}$ size, US nano, $1000 \mathrm{mg} \mathrm{L}^{-1}$ concentration) incubated for $3 \mathrm{~h}$ in simulated sludge solution (10 $\mathrm{mg} \mathrm{L}^{-1}$ humic acid adjusted to $\mathrm{pH} 4.5$ ). These results are presented in Figure S5 (Section S4, Supporting Information).

\section{REFERENCES}

(1) Sun, T. Y.; Gottschalk, F.; Hungerbühler, K.; Nowack, B. Comprehensive Probabilistic Modelling of Environmental Emissions of Engineered Nanomaterials. Environ. Pollut. 2014, 185, 69-76.

(2) Ma, R.; Levard, C.; Judy, J. D.; Unrine, J. M.; Durenkamp, M.; Martin, B.; Jefferson, B.; Lowry, G. V. Fate of Zinc Oxide and Silver Nanoparticles in a Pilot Wastewater Treatment Plant and in Processed Biosolids. Environ. Sci. Technol. $2014,48,104-112$.

(3) Gottschalk, F.; Sonderer, T.; Scholz, R. W.; Nowack, B. Modeled

Environmental Concentrations of Engineered Nanomaterials (TiO2, ZnO, Ag, CNT, Fullerenes) for 
Different Regions. Environ. Sci. Technol. 2009, 43, 9216-9222.

(4) Tan, M.; Qiu, G.; Ting, Y.-P. Effects of ZnO Nanoparticles on

Wastewater Treatment and Their Removal Behavior in a Membrane Bioreactor. Bioresour. Technol. 2015, 185, 125-133.

(5) Wang, M. M.; Wang, J.; Cao, R.; Wang, S. Y.; Du, H. Natural

Transformation of Zinc Oxide Nanoparticles and Their Cytotoxicity and Mutagenicity. J. Nanomater. 2017, 2017, 8457960.

(6) Meli, K.; Kamika, I.; Keshri, J.; Momba, M. N. B. The Impact of Zinc Oxide Nanoparticles on the Bacterial Microbiome of Activated Sludge Systems. Sci. Rep. 2016, 6, 39176.

(7) Hou, J.; Wu, Y.; Li, X.; Wei, B.; Li, S.; Wang, X. Toxic Effects of Different Types of Zinc Oxide Nanoparticles on Algae, Plants, Invertebrates, Vertebrates and Microorganisms. Chemosphere 2018, 193, 852-860.

(8) Durenkamp, M.; Pawlett, M.; Ritz, K.; Harris, J. A.; Neal, A. L.;

McGrath, S. P. Nanoparticles within WWTP Sludges Have Minimal

Impact on Leachate Quality and Soil Microbial Community Structure and Function. Environ. Pollut. 2016, 211,399-405.

(9) Dale, A. L.; Lowry, G. V.; Casman, E. A. Stream Dynamics and

Chemical Transformations Control the Environmental Fate of Silver and Zinc Oxide Nanoparticles in a Watershed-Scale Model. Environ. Sci. Technol. 2015, 49, 7285-7293.

(10) Lowry, G. V.; Gregory, K. B.; Apte, S. C.; Lead, J. R.

Transformations of Nanomaterials in the Environment. Environ. Sci. Technol. 2012, 46, 6893-6899.

(11) Garner, K. L.; Keller, A. A. Emerging Patterns for Engineered

Nanomaterials in the Environment: A Review of Fate and Toxicity Studies. J. Nanopart. Res. 2014, 16, 2503.

(12) Maurer-Jones, M. A.; Gunsolus, I. L.; Murphy, C. J.; Haynes, C.

L. Toxicity of Engineered Nanoparticles in the Environment. Anal. Chem. 2013, 85, 3036-3049.

(13) Casas, A. M.; Crecelius, E. A. Relationship between Acid

Volatile Sulfide and the Toxicity of Zinc, Lead and Copper in Marine Sediments. Environ. Toxicol. Chem. 1994, 13, 529-536.

(14) Di Toro, D. M.; McGrath, J. A.; Hansen, D. J.; Berry, W. J.;

Paquin, P. R.; Mathew, R.; Wu Kuen, B.; Santore, R. C. Predicting Sediment Metal Toxicity Using a

Sediment Biotic Ligand Model: Methodology and Initial Application. Environ. Toxicol. Chem. 2005, 24,

2410-2427.

(15) Lombi, E.; Donner, E.; Tavakkoli, E.; Turney, T. W.; Naidu, R.;

Miller, B. W.; Scheckel, K. G. Fate of Zinc Oxide Nanoparticles during

Anaerobic Digestion of Wastewater and Post-Treatment Processing of Sewage Sludge. Environ. Sci.

Technol. 2012, 46, 9089-9096.

(16) Ma, R.; Levard, C.; Michel, F. M.; Brown, G. E.; Lowry, G. V.

Sulfidation Mechanism for Zinc Oxide Nanoparticles and the Effect of Sulfidation on Their Solubility.

Environ. Sci. Technol. 2013, 47, 2527- 2534.

(17) Neale, P. A.; Jamting, A. K.; O’Malley, E.; Herrmann, J.; Escher,

B. I. Behaviour of Titanium Dioxide and Zinc Oxide Nanoparticles in

the Presence of Wastewater-Derived Organic Matter and Implications for Algal Toxicity. Environ. Sci.:

Nano 2015, 2, 86-93.

(18) Praetorius, A.; Scheringer, M.; Hungerbühler, K. Development

of Environmental Fate Models for Engineered Nanoparticles A Case Study of $\mathrm{TiO}_{2}$ Nanoparticles in the

Rhine River. Environ. Sci. Technol.

2012, 46, 6705-6713.

(19) Quik, J. T. K.; Velzeboer, I.; Wouterse, M.; Koelmans, A. A.; van

de Meent, D. Heteroaggregation and Sedimentation Rates for Nanomaterials in Natural Waters. Water Res. 2014, 48, 269-279.

(20) Bian, S.-W.; Mudunkotuwa, I. A.; Rupasinghe, T.; Grassian, V.

$\mathrm{H}$. Aggregation and Dissolution of $4 \mathrm{Nm} \mathrm{ZnO}$ Nanoparticles in

Aqueous Environments: Influence of $\mathrm{pH}$, lonic Strength, Size, and Adsorption of Humic Acid. Langmuir 2011, 27, 6059-6068.

(21) Chen, S.; Goode, A. E.; Skepper, J. N.; Thorley, A. J.; Seiffert, J.

M.; Chung, K. F.; Tetley, T. D.; Shaffer, M. S. P.; Ryan, M. P.; Porter,

A. E. Avoiding Artefacts during Electron Microscopy of Silver Nanomaterials Exposed to Biological 
Environments. J. Microsc. 2016, 261, 157-166.

(22) Porter, A. E.; Gass, M.; Muller, K.; Skepper, J. N.; Midgley, P. A.;

Welland, M. Direct Imaging of Single-Walled Carbon Nanotubes in Cells. Nat. Nanotechnol. 2007, 2, 713-717.

(23) Punshon, T.; Guerinot, M. L.; Lanzirotti, A. Using Synchrotron

X-Ray Fluorescence Microprobes in the Study of Metal Homeostasis in Plants. Ann. Bot. 2009, 103, 665-672.

(24) Chen, S.; Deng, J.; Yuan, Y.; Flachenecker, C.; Mak, R.;

Hornberger, B.; Jin, Q.; Shu, D.; Lai, B.; Maser, J.; Roehrig, C.; Paunesku, T.; Gleber, S. C.; Vine, D. J.; Finney, L.; VonOsinski, J.; Bolbat, M.; Spink, I.; Chen, Z.; Steele, J. The Bionanoprobe: Hard X- Ray Fluorescence Nanoprobe with Cryogenic Capabilities. J.

Synchrotron Radiat. 2014, 21, 66-75.

(25) Yuan, Y.; Chen, S.; Paunesku, T.; Gleber, S. C.; Liu, W. C.;

Doty, C. B.; Mak, R.; Deng, J.; Jin, Q.; Lai, B.; Brister, K.; Flachenecker, C.; Jacobsen, C.; Vogt, S.; Woloschak, G. E. Epidermal Growth Factor Receptor Targeted Nuclear Delivery and High-

Resolution Whole Cell X-Ray Imaging of Fe3O4@TiO2 Nanoparticles in Cancer Cells. ACS Nano 2013, 7, 10502-10517.

(26) Kaulich, B.; Thibault, P.; Gianoncelli, A.; Kiskinova, M. Transmission and Emission X-Ray Microscopy: Operation Modes, Contrast Mechanisms and Applications. J. Phys.: Condens. Matter 2011, 23, 083002.

(27) Vila-Comamala, J.; Pan, Y. S.; Lombardo, J. J.; Harris, W. M.; Chiu, W. K. S.; David, C.; Wang, Y. X. Zone-Doubled Fresnel Zone

Plates for High-Resolution Hard X-Ray Full-Field Transmission Microscopy. J. Synchrotron Radiat. 2012, $19,705-709$.

(28) Nazaretski, E.; Lauer, K.; Yan, H.; Bouet, N.; Zhou, J.; Conley,

R.; Huang, X.; Xu, W.; Lu, M.; Gofron, K.; Kalbfleisch, S.; Wagner, U.; Rau, C.; Chu, Y. S. Pushing the Limits:

An Instrument for Hard X-Ray

Imaging below $20 \mathrm{~nm}$. J. Synchrotron Radiat. 2015, 22, 336-341.

(29) Yan, H.; Nazaretski, E.; Lauer, K.; Huang, X.; Wagner, U.; Rau,

C.; Yusuf, M.; Robinson, I.; Kalbfleisch, S.; Li, L.; Bouet, N.; Zhou, J.; Conley, R.; Chu, Y. S. Multimodality Hard-X-Ray Imaging of a Chromosome with Nanoscale Spatial Resolution. Sci. Rep. 2016, 6, 20112.

(30) Maiden, A. M.; Rodenburg, J. M. An Improved Ptychographical Phase Retrieval Algorithm for Diffractive Imaging. Ultramicroscopy 2009, 109, 1256-1262.

(31) Twining, B. S.; Baines, S. B.; Fisher, N. S.; Maser, J.; Vogt, S.; Jacobsen, C.; Tovar-Sanchez, A.; SañudoWilhelmy, S. A. Quantifying Trace Elements in Individual Aquatic Protist Cells with a Synchrotron

X-Ray Fluorescence Microprobe. Anal. Chem. 2003, 75, 3806-3816.

(32) Kosior, E.; Bohic, S.; Suhonen, H.; Ortega, R.; Deves, G.;

Carmona, A.; Marchi, F.; Guillet, J. F.; Cloetens, P. Combined Use of Hard X-Ray Phase Contrast Imaging and X-Ray Fluorescence Microscopy for Sub-Cellular Metal Quantification. J. Struct. Biol.

2012, 177, 239-247.

(33) Fahrni, C. J. Biological Applications of X-Ray Fluorescence

Microscopy: Exploring the Subcellular Topography and Speciation of Transition Metals. Curr. Opin. Chem. Biol. 2007, 11, 121-127.

(34) Manceau, A.; Marcus, M. A.; Tamura, N.; Proux, O.; Geoffroy, N.; Lanson, B. Natural Speciation of Zn at the Micrometer Scale in a Clayey Soil Using X-Ray Fluorescence, Absorption, and Diffraction.

Geochim. Cosmochim. Acta 2004, 68, 2467-2483.

(35) Panfili, F.; Manceau, A.; Sarret, G.; Spadini, L.; Kirpichtchikova,

T.; Bert, V.; Laboudigue, A.; Marcus, M. A.; Ahamdach, N.; Libert, M.-

F. The Effect of Phytostabilization on Zn Speciation in a Dredged Contaminated Sediment Using Scanning Electron Microscopy, X-Ray

Fluorescence, EXAFS Spectroscopy, and Principal Components Analysis. Geochim. Cosmochim. Acta 2005, 69, 2265-2284.

(36) Hernandez-Viezcas, J. A.; Castillo-Michel, H.; Andrews, J. C.;

Cotte, M.; Rico, C.; Peralta-Videa, J. R.; Ge, Y.; Priester, J. H.; Holden,

P. A.; Gardea-Torresdey, J. L. In Situ Synchrotron X-Ray Fluorescence 
Mapping and Speciation of $\mathrm{CeO}_{2}$ and $\mathrm{ZnO}$ Nanoparticles in Soil Cultivated Soybean (Glycine max). ACS Nano 2013, 7 (2), 1415-

1423.

(37) Ravel, B.; Newville, M. ATHENA, ARTEMIS, HEPHAESTUS: Data Analysis for X-Ray Absorption Spectroscopy Using IFEFFIT. J. Synchrotron Radiat. 2005, 12, 537-541.

(38) Calderon, L.; Han, T. T.; McGilvery, C. M.; Yang, L.;

Subramaniam, P.; Lee, K. B.; Schwander, S.; Tetley, T. D.; Georgopoulos, P. G.; Ryan, M.; Porter, A. E.; Smith, R.; Chung, K. F.; Lioy, P. J.; Zhang, J.; Mainelis, G. Release of Airborne Particles and Ag and Zn Compounds from Nanotechnology-Enabled Consumer Sprays: Implications for Inhalation Exposure. Atmos. Environ. 2017,

$155,85-96$.

(39) Xie, F.; Centeno, A.; Zou, B.; Ryan, M. P.; Riley, D. J.; Alford, N.

M. Tunable Synthesis of Ordered Zinc Oxide Nanoflower-Like A'rrays.

J. Colloid Interface Sci. 2013, 395, 85-90.

(40) Wang, T.; Costan, J.; Centeno, A.; Pang, J. S.; Darvill, D.; Ryan,

M. P.; Xie, F. Broadband Enhanced Fluorescence Using Zinc-Oxide Nanoflower Arrays. J. Mater. Chem. C 2015, 3, 2656-2663.

(41) Kaegi, R.; Voegelin, A.; Sinnet, B.; Zuleeg, S.; Hagendorfer, H.;

Burkhardt, M.; Siegrist, H. Behavior of Metallic Silver Nanoparticles in a Pilot Wastewater Treatment Plant. Environ. Sci. Technol. 2011, 45, 3902-3908.

(42) Reed, N. M.; Cairns, R. O.; Hutton, R. C.; Takaku, Y.

Characterization of Polyatomic Ion Interferences in Inductively Coupled Plasma Mass Spectrometry

Using a High Resolution Mass

Spectrometer. J. Anal. At. Spectrom. 1994, 9, 881-896.

(43) Kelly, S. D.; Hesterberg, D.; Ravel, B. Analysis of Soils and

Minerals Using X-Ray Absorption Spectroscopy; Ulery, A. L., Dress, R., Eds.; Methods of Soil Analysis: Part

5, Mineralogical methods; Soil Science Society of America: Madison, WI, 2008; pp 387-464.

(44) Newbury, D. E.; Ritchie, N. W. M. Is Scanning Electron

Microscopy/Energy Dispersive X-ray Spectrometry (SEM/EDS) Quantitative? Scanning 2013, 35, 141-168.

(45) Rathnayake, S.; Unrine, J. M.; Judy, J.; Miller, A.-F.; Rao, W.;

Bertsch, P. M. Multitechnique Investigation of the PH Dependence of Phosphate Induced Transformations of ZnO Nanoparticles. Environ. Sci. Technol. 2014, 48, 4757-4764.

(46) Lv, J.; Zhang, S.; Luo, L.; Han, W.; Zhang, J.; Yang, K.; Christie,

P. Dissolution and Microstructural Transformation of ZnO Nano- particles under the Influence of Phosphate. Environ. Sci. Technol. 2012, 46, 7215-7221.

(47) Le Bars, M.; Legros, S.; Levard, C.; Chaurand, P.; Tella, M.; Rovezzi, M.; Browne, P.; Rose, J.; Doelsch, E. Drastic Change in Zinc Speciation during Anaerobic Digestion and Composting: Instability of Nanosized Zinc Sulfide. Environ. Sci. Technol. 2018, 52, 12987-12996.

(48) Philippe, A.; Schaumann, G. E. Interactions of Dissolved

Organic Matter with Natural and Engineered Inorganic Colloids: A Review. Environ. Sci. Technol. 2014, 48, 8946-8962.

(49) Zhang, Y.; Chen, Y.; Westerhoff, P.; Crittenden, J. Impact of

Natural Organic Matter and Divalent Cations on the Stability of Aqueous Nanoparticles. Water Res. 2009, 43, 4249-4257.

(50) Jiang, C.; Aiken, G. R.; Hsu-Kim, H. Effects of Natural Organic

Matter Properties on the Dissolution Kinetics of Zinc Oxide Nanoparticles. Environ. Sci. Technol. 2015, 49, $11476-11484$.

(51) Yoon, T. H.; Johnson, S. B.; Brown, G. E. Adsorption of Organic

Matter at Mineral/Water Interfaces. IV. Adsorption of Humic Substances at Boehmite/Water Interfaces

and Impact on Boehmite

Dissolution. Langmuir 2005, 21, 5002-5012.

(52) Degen, A.; Kosec, M. Effect of pH and Impurities on the Surface Charge of Zinc Oxide in Aqueous

Solution. J. Eur. Ceram. Soc. 2000, 20,667-673.

(53) Wang, P.; Menzies, N. W.; Lombi, E.; McKenna, B. A.;

Johannessen, B.; Glover, C. J.; Kappen, P.; Kopittke, P. M. Fate of ZnO Nanoparticles in Soils and Cowpea

(Vigna Unguiculata). Environ. Sci. Technol. 2013, 47, 13822-13830.

(54) Cho, W.-S.; Duffin, R.; Howie, S. E. M.; Scotton, C. J.; Wallace,

W. A. H.; MacNee, W.; Bradley, M.; Megson, I. L.; Donaldson, K. Progressive Severe Lung Injury by Zinc 
Oxide Nanoparticles; the Role of $\mathrm{Zn}^{2+}$ Dissolution inside Lysosomes. Part. Fibre Toxicol. 2011, 8, 27.

(55) Illy, B. N.; Cruickshank, A. C.; Schumann, S.; Da Campo, R.; Jones, T. S.; Heutz, S.; McLachlan, M. A.; McComb, D. W.; Riley, D. J.; Ryan, M. P. Electrodeposition of ZnO Layers for Photovoltaic Applications: Controlling Film Thickness and Orientation. J. Mater.

Chem. 2011, 21, 12949-12957.

(56) Basham, M.; Filik, J.; Wharmby, M. T.; Chang, P. C. Y.; El

Kassaby, B.; Gerring, M.; Aishima, J.; Levik, K.; Pulford, B. C. A.; Sikharulidze, I.; Sneddon, D.; Webber, M.; Dhesi, S. S.; Maccherozzi, F.; Svensson, O.; Brockhauser, S.; Naray, G.; Ashton, A. W. Data Analysis WorkbeNch (DAWN). J. Synchrotron Radiat. 2015, 22, 853858.

(57) Koronfel, M. A.; Goode, A. E.; Gomez-Gonzalez, M. A.; Weker,

J. N.; Simoes, T. A.; Brydson, R.; Quinn, P.; Toney, M. F.; Hart, A.; Porter, A. E.; Ryan, M. P. Chemical Evolution of CoCrMo Wear Particles: An In Situ Characterization Study. J. Phys. Chem. C 2019, 123, 9894-9901.

(58) Cismasu, A. C.; Levard, C.; Michel, F. M.; Brown, G. E.

Properties of Impurity-Bearing Ferrihydrite II: Insights into the Surface Structure and Composition of Pure, Al- and Si-Bearing

Ferrihydrite from Zn(II) Sorption Experiments and Zn K-Edge X-Ray Absorption Spectroscopy. Geochim. Cosmochim. Acta 2013, 119, 4660.

M

DOI: $10.1021 / a c s n a n o .9 b 02866$

ACS Nano XXXX, XXX, XXX-XXX 